\title{
Karakterisasi Sistem Dispersi Padat Meloksikam Dengan Matriks PEG 6000 Dan Poloxamer 188 Dibuat Dengan Menggunakan Metode Peleburan
}

\author{
Yuli Ainun Najih*1, Yuyun Nailufa ${ }^{1}$, Dita Nurlita Rakhma ${ }^{1}$, Bambang Widjaja ${ }^{1}$, Lailatul Silviyah ${ }^{1}$, Choirun $^{1}$ \\ Mujahida $^{1}$ \\ ${ }^{1}$ Program Studi Farmasi, Fakultas Kedokteran, Universitas Hang Tuah, Surabaya, Indonesia
}

*E-mail: yuli.najih@ hangtuah.ac.id

\begin{abstract}
Meloxicam is included in the class II Biopharmaceutical Classification System (BCS). This drug has low solubility and high permeability. The solubility is one of the factors that affect in the dissolution rate of drug. One of the effort to increase dissolution of meloxicam is by forming a solid dispersion system made using melting method. The addition of PEG 6000 and poloxamer 188 carriers determine in the solid dispersion system aims to increase the dissolution rate of meloxicam. The purpose of this study is to characterize the meloxicam solid dispersion system with PEG 6000 and poloxamer 188 matrices at a ratio of 99:1 and 98:2 made by the melting method when compared with the physical mixture and its pure compound using Powder X-Ray Diffaction, DSC and FTIR. The results of meloxicam solid dispersion with a ratio 99:1 and 98:2 showed the disappearance of the typical peak of meloxicam at an angel of $206.5^{\circ}$ and $11.2^{\circ}$. The thermogram data using DSC shows a decrease in melting point of solid dispersion system with a ratio of $99: 1$ and $98: 2$ namely $64.33^{\circ} \mathrm{C}$ and $64.21^{\circ} \mathrm{C}$. The result of the characterization of meloxicam solid dispersion with FTIR showed that the identified spectrum were in the spectrum range of meloxicam, PEG 6000, poloxamer 188 indicating there was no incteraction in the meloxicam solid dispersion system.
\end{abstract}

Keywords: Meloxicam, PEG 6000, Poloxamer 188, Solid Dispersion, Melting Method, Characterization

\section{Pendahuluan}

Meloksikam adalah obat antiinflamasi yang digunakan untuk pengobatan gangguan musculoskeletal dan sendi seperti rheumatoid arthritis dan osteoarthritis baik akut maupun kronik [1]. Mekanisme kerja dari meloksikam yaitu lebih menghambat cyclooxygenase 2 (COX-2) dibandingkan cyclooxygenase 1 (COX-1) [2]. Meloksikam tergolong dalam klasifikasi Biopharmaceutical Classification System (BCS) kelas II yang memiliki permeabilitas tinggi dan kelarutan rendah yaitu meloksikam praktis tidak larut air $(0,012 \mathrm{~g} / \mathrm{L})$ [3]. Peningkatan bioavailabilitas obat per oral dengan kelarutan rendah dalam air menjadi salah satu tantangan tersendiri dalam pengembangan obat meskipun telah banyak metode pengembangannya antara lain pembentukan garam, penambahan bahan untuk meningkatkan kelarutan, pengecilan ukuran partikel dengan dibuat nanosuspensi, dan sistem dispersi padat [4][5].

Dispersi padat merupakan suatu campuran satu atau lebih bahan aktif dalam pembawa yang bersifat inert untuk mendapatkan laju disolusi dan bioavailabilitas yang lebih baik daripada bahan aktif yang sukar larut dalam air [6]. Sistem dispersi padat dapat dibuat salah satunya dengan metode peleburan [7]. Metode peleburan dilakukan dengan cara mencampurkan suatu obat dengan pembawa dan dipanaskan hingga melebur, kemudian leburan dipadatkan [8]. Keuntungan menggunakan metode peleburan yaitu ekonomis, tidak memerlukan pelarut, metodenya sederhana dan kualitas produk yang seragam [9]. 
Penambahan bahan pembawa polimer dan surfaktan sering dilakukan dalam pembutan sistem dispersi padat. Polimer yang sering digunakan dalam sistem dispersi padat yaitu PEG 6000 [10]. PEG secara luas digunakan sebagai pembawa untuk dispersi padat karena memiliki titik leleh yang rendah, tingkat pembekuan yang cepat, kemampuan membentuk larutan padat dan toksisitas rendah [11]. Keuntungan menambahkan bahan pembawa PEG 6000 yaitu dapat mengubah partikel obat menjadi lebih amorf sehingga hasil disolusi obat lebih baik [10]. Sedangkan surfaktan nonionik yang paling banyak digunakan salah satunya adalah poloxamer 188 [12]. Poloxamer 188 terdiri dari etilen oksida dan propilen oksida yang bersifat hidrofilikdan sangat mudah larut dalam air dan etanol 98\% [13]. Keuntungan menambahkan poloxamer 188 dalam sistem dispersi padat adalah untuk meningkatkan laju disolusi bahan obat dengan cara pengurangan agregasi partikel obat [14]. Tujuan penelitian ini yaitu karakterisasi sistem dispersi padat meloksikam dengan matriks PEG 6000 dan poloxamer 188 dibuat dengan menggunakan metode peleburan dengan perbandingan konsentrasi polimer:surfaktan (99:1) dan (98:2).

\section{Bahan dan Metode}

\subsection{Bahan}

Bahan-bahan yang digunakan dalam penelitian ini antara lain meloksikam p.g (Hangzhou DingyanChem Co., LTD, China), PEG 6000 p.a, Poloxamer 188 p.g, aquadest.

\subsection{Metode}

Pembentukan sistem dispersi padat meloksikam dibuat menggunakan metode peleburan dengan cara menimbang masing-masing bahan baku meloksikam, PEG 6000, dan poloxamer 188 dengan perbandingan (99:1) dan (98:2). Panaskan campuran meloksikam, PEG 6000 dan poloxamer 188 di atas hot plate dengan suhu $56^{\circ} \mathrm{C}$ selama 10 menit sampai 15 menit hingga campuran meleleh. Kemudian hasil lelehan di simpan pada suhu $-5^{\circ} \mathrm{C}$ selama 24 jam menggunakan dry ice sampai diperoleh padatan kembali. Selanjutnya padatan dihancurkan menjadi serbuk dan diayak menggunakan ayakan 60 mesh. Serbuk yang sudah diayak dilakukan karakterisasi menggunakan Powder X-Ray Diffraction (PXRD), Differential Scanning Calorimetry (DSC) dan Fourier Transform Infrared (FTIR).

\section{Hasil dan Pembahasan}

\subsection{Karakterisasi menggunakan Powder X-Ray Diffraction (PXRD)}

Karakterisasi menggunakan PXRD dilakukan pada sampel meloksikam tunggal (MLX), PEG 6000 (PEG), poloxamer
188 (PLX), campuran fisik meloksikam-PEG 6000poloxamer 188 (99:1) (CF-1), campuran fisik-PEG 6000poloxamer 188 (98:2)(CF-2), dispersi padat-PEG 6000poloxamer 188 (99:1) (DP-2) dan dispersi padat-PEG 6000poloxamer 188 (99:1) (DP-2). Sampel ditimbang masingmasing 5-10 mg lalu dimasukkan kedalam glass holder hingga penuh. Glass holder yang sudah terisi oleh sampel kemudian dimasukkan kedalam instrumen PXRD. Suhu yang digunakan yaitu suhu ruang dan diamati pada sudut $2 \theta=$ $5,0^{\circ}-50,0^{\circ}[15]$.

Difraktogram hasil karakterisasi dengan PXRD dapat dilihat pada Tabel 1 dan Gambar 1 menunjukkan adanya puncak tajam yang spesifik dari meloksikam, PEG 6000 dan poloxamer 188. Puncak tajam pada difraktogram menunjukkan bahwa senyawa tersebut dalam bentuk kristalin. Senyawa meloksikam murni menunjukkan puncak yang tajam dan khas pada sudut $2 \theta\left(6,5^{\circ} ; 13,0^{\circ} ; 18,5^{\circ}\right.$; dan $23,5^{\circ}$ ). Difraktogram PEG 6000 menunjukkan karakteristik sudut $2 \theta\left(23,5^{\circ}\right)$. Sedangkan pada poloxamer 188 menunjukkan puncak khas pada sudut $2 \theta\left(23,5^{\circ}\right)$. Pada DP-1 diperoleh hilangnya puncak pada sudut $6,5^{\circ}$ dan terbentuknya puncak dengan tingkat ketajaman atau instensitas yang lebih kecil pada sudut $13,5^{\circ} ; 15,0^{\circ}$; dan $18,5^{\circ}$. Sedangkan pada DP-2 diperoleh puncak dengan intensitas sebesar 2,16 pada sudut $13,5^{\circ}$, begitu pula pada sudut $2 \theta$ lainnya nilai intensitasnya lebih kecil. Difraktogram pada pembentukan sistem dispersi padat dengan metode peleburan tersebut menunjukkan adanya perubahan bentuk puncak dengan intensitas yang lebih kecil, dimana hal tersebut menunjukkan bahwa telah terjadi adanya perubahan dari fase kristalin menjadi lebih amorf [16]. Kemudian jika dibandingkan hasil difraktogram antara DP-1 dan DP-2 terdapat perbedaan selisih nilai intensitas tidak terlalu jauh berbeda.

\subsection{Karakterisasi menggunakan Differential Scanning Calorimetry (DSC)}

Karakterisasi thermal dilakukan dengan menggunakan instrumen DSC dengan sampel meloksikam tunggal (MLX), PEG 6000 (PEG), poloxamer 188 (PLX), campuran fisik meloksikam-PEG 6000-poloxamer 188 (99:1) (CF-1), campuran fisik -PEG 6000-poloxamer 188 (98:2) (CF-2), dispersi padat-PEG 6000-poloxamer 188 (99:1) (DP-2) dan dispersi padat-PEG 6000-poloxamer 188 (99:1) (DP-2). Sampel ditimbang masing-masing 5-10 mg dan dipindahkan dalam pan alumunium kemudian dimasukkan kedalam instrumen DSC. Instrumen DSC diatur dengan kecepatan pemanasan $10^{\circ} \mathrm{C} /$ menit dan diamati pada rentang suhu $30^{\circ} \mathrm{C}$ $300^{\circ} \mathrm{C}[15]$.

Data Termogram DSC dapat dilihat pada Tabel 2 dan Gambar 2. Hasil termogram dari meloksikam menunjukkan puncak endotermik $264,82^{\circ} \mathrm{C}$ yang hasilnya mendekati 
dengan penelitian sebelumnya yaitu $260^{\circ} \mathrm{C}$ [15], sedangkan puncak endotermik dari PEG 6000 berada pada suhu $65,33^{\circ} \mathrm{C}$ dan poloxamer 188 berada pada suhu $56,20^{\circ} \mathrm{C}$. Hasil termogram DSC dari sistem dispersi padat mengalami penurunan puncak endotermik dibandingkan dengan meloksikam murni yaitu $64,33^{\circ} \mathrm{C}$ pada DP-1 dan $64,21^{\circ} \mathrm{C}$ pada DP-2. Dari termogram tersebut menunjukkan bahwa terjadi pergeseran titik lebur pada campuran fisik dan dispersi padat dibandingkan dengan meloksikam murni. Hal tersebut menunjukkan bahwa derajat kristalinitas telah berkurang pada hasil termogram menggunakan DSC. Data termogram DSC secara keseluruhan sistem dispersi padat pada masing-masing formula menunjukkan pergeseran titik lebur di antara titik lebur PEG 6000 dan poloxamer 188. Hal ini mendukung pernyataan bahwa sifat-sifat dispersi padat mengikuti sifat karakteristik dari pembawanya yaitu PEG 6000 dan poloxamer 188 [15].

\subsection{Karakterisasi menggunakan Fourier Transform Infrared (FTIR)}

Fourier Transform Infrared (FTIR) merupakan instrumen yang digunakan untuk memberikan informasi adanya interaksi antar gugus fungsi pada bahan yang digunakan dalam pembentukan dispersi padat. Spektra infrared meloksikam (MLX), PEG 6000 (PEG), poloxamer 188 (PLX), campuran fisik meloksikam-PEG 6000-poloxamer 188 (99:1) (CF-1), campuran fisik -PEG 6000-poloxamer 188 (98:2) (CF-2), dispersi padat-PEG 6000-poloxamer 188 (99:1) (DP-2) dan dispersi padat-PEG 6000-poloxamer 188 (99:1) (DP-2) diperiksa menggunakan metode pelet $\mathrm{KBr}$. Sebesar $1 \% \mathrm{~b} / \mathrm{b}$ sampel $\mathrm{KBr}$ disiapkan dengan cara menggerus serbuk sampel dan $\mathrm{KBr}$ dalam mortir hingga homogen. Kemudian campuran tersebut dimasukkan kedalam vakum pengering lalu ditekan dengan penekan hidrolik hingga diperoleh cakram transparan. Cakram yang terbentuk diletakkan pada sample holder dan disinari dengan cahaya infarmerah, lalu diamati pita serapan pada gelombang $4000-400 \mathrm{~cm}^{-1}$ [17].

Hasil spektra inframerah dapat dlihat pada Tabel 3 dan Gambar 3 menunjukkan terjadi pergeseran gugus $\mathrm{N}-\mathrm{H}$ dan $\mathrm{S}=\mathrm{O}$. Dua gugus tersebut berperan dalam pembentukan ikatan hidrogen antara meloksikam dengan PEG 6000. Spektra inframerah gugus N-H pada meloksikam murni berada pada bilangan gelombang $3290 \mathrm{~cm}^{-1}$. Pita serapan gugus $\mathrm{S}=\mathrm{O}$ juga mengalami pergeseran dari bilangan gelombang $1346 \mathrm{~cm}^{-1}$ pada meloksikam murni menjadi 1344 $\mathrm{cm}^{-1}$ pada dispersi padat.

Spektra FTIR dari DP-1 dan DP-2 juga menunjukkan tidak ada pergeseran pita serapan yang tajam pada bilangan gelombang meloksikam, PEG 6000 dan poloxamer 188. Hal tersebut menunjukkan bahwa tidak terbentuknya interaksi yang dapat mempengaruhi struktur meloksikam dan tidak mempengaruhi efek terapi meloksikam dengan pembawa yang digunakan. Hasil spektra FTIR sistem dipersi padat dalam penelitian ini terjadi juga pada penelitian sistem dispersi padat glikazid yang terbentuk bahwa tidak terjadi pergeseran bilangan gelombang dibandingkan campuran fisik dan meloksikam. Interaksi terjadi antara bahan aktif dengan pembawa jika pergeseran bilangan gelombang pada gugus fungsi $\mathrm{C}=\mathrm{O}, \quad \mathrm{S}=\mathrm{O}, \quad \mathrm{N}-\mathrm{H} \quad[18]$.

Tabel 1. Intensitas meloksikam, PEG 6000, poloxamer 188, campuran fisik (99:1) (CF-1), campuran fisik (98:2), dispersi padat (99:1) (DP-1) dan dispersi padat (98:2) (DP-2).

\begin{tabular}{|c|c|c|c|c|c|c|c|c|}
\hline \multirow{3}{*}{ No. } & \multirow[b]{3}{*}{$2 \theta$} & \multicolumn{7}{|c|}{ Intensitas Relatif (\%) } \\
\hline & & \multirow[b]{2}{*}{ Meloksi-kam } & \multirow[b]{2}{*}{ PEG 6000} & \multirow[b]{2}{*}{ Poloxa-mer 188} & \multicolumn{2}{|c|}{ Campuran Fisik } & \multicolumn{2}{|c|}{ Dispersi Padat } \\
\hline & & & & & CF-1 (99:1) & CF-2 (98:2) & $\begin{array}{c}\text { DP-1 } \\
(99: 1)\end{array}$ & $\begin{array}{c}\text { DP-2 } \\
(98: 2)\end{array}$ \\
\hline 1. & 5,2 & - & 0,85 & - & - & - & - & - \\
\hline 2. & 6,5 & 24,40 & - & - & - & - & - & - \\
\hline 3. & 11,2 & 4,49 & - & - & - & - & - & - \\
\hline 4. & 13,5 & 14,58 & 16,25 & 0,96 & 14,16 & 10,97 & 2,54 & 2,16 \\
\hline 5. & 15,0 & 77,65 & 11,14 & 3,60 & 12,24 & 10,72 & 6,41 & 5,51 \\
\hline 6. & 18,5 & 50,94 & 15,51 & - & 13,44 & 13,70 & 7,13 & 6,20 \\
\hline 7. & 21,0 & - & 7,38 & 5,33 & 6,06 & 5,90 & 3,80 & 3,57 \\
\hline 8. & 23,5 & 6,59 & 92,73 & 93,11 & 90,48 & 77,67 & 58,68 & 49,35 \\
\hline 9. & 26,2 & 19,24 & 4,28 & 8,27 & 9,04 & 7,52 & 9,65 & 9,28 \\
\hline 10. & 27,7 & - & 7,70 & 2,55 & 6,20 & 6,90 & 3,81 & 2,89 \\
\hline
\end{tabular}




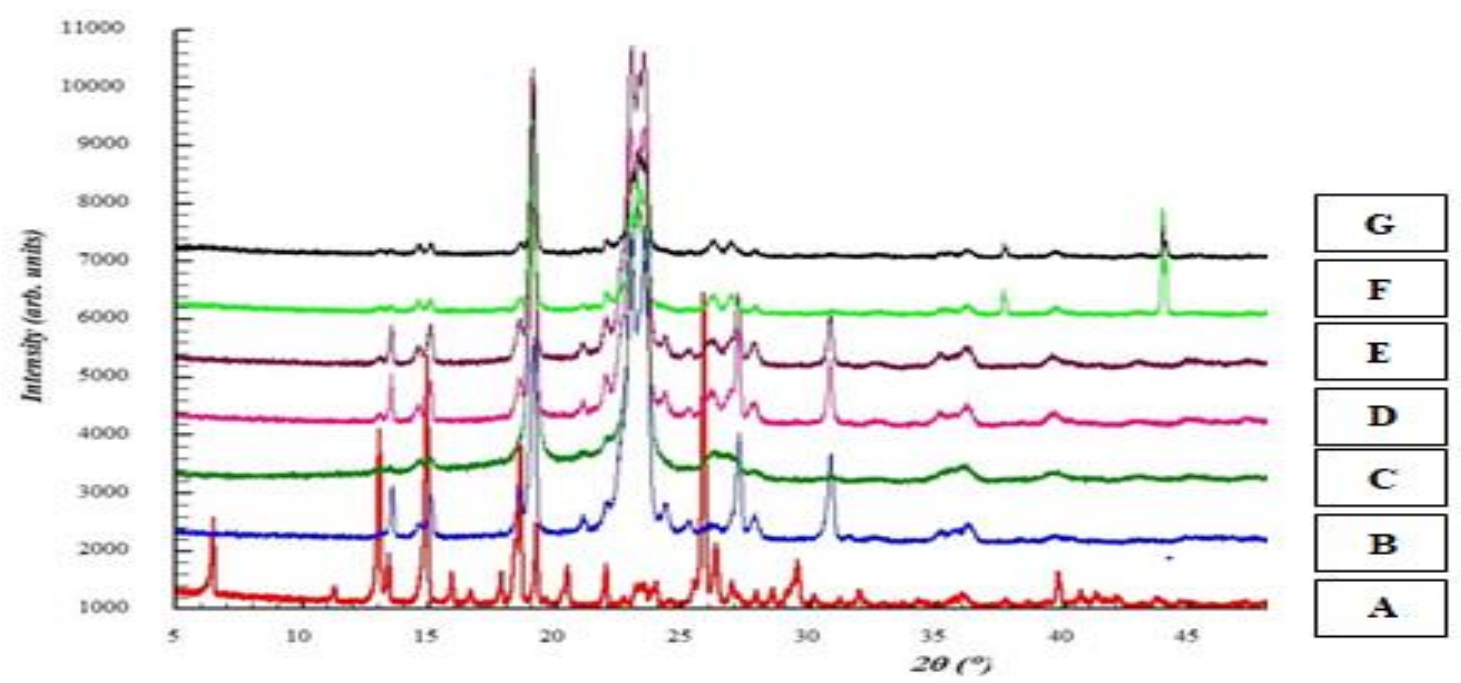

Gambar 1. Perbandingan Difraktogram (A) MLX, (B) PEG, (C) PLX, (D) CF-1, (E) CF-2, (F) DP-1, (G) DP-2.

Tabel 2. Puncak endotermik meloksikam, PEG 6000, poloxamer 188, campuran fisik (99:1) (CF-1), campuran fisik (99:2) (CF-2), dispersi padat (99:1) (DP-1) dan dispersi padat (98:2) (DP-2).

\begin{tabular}{ccc}
\hline No. & Sampel & Puncak Endotermik $\left({ }^{\circ} \mathbf{C}\right)$ \\
\hline $\mathbf{1 .}$ & Meloksikam & 264,82 \\
2. & PEG 6000 & 65,33 \\
3. & Poloxamer 188 & 56,20 \\
4. & CF-1 & 66,21 \\
5. & CF-2 & 65,69 \\
6. & DP-1 & 64,21 \\
7. & DP-2 & 64,33 \\
\hline
\end{tabular}

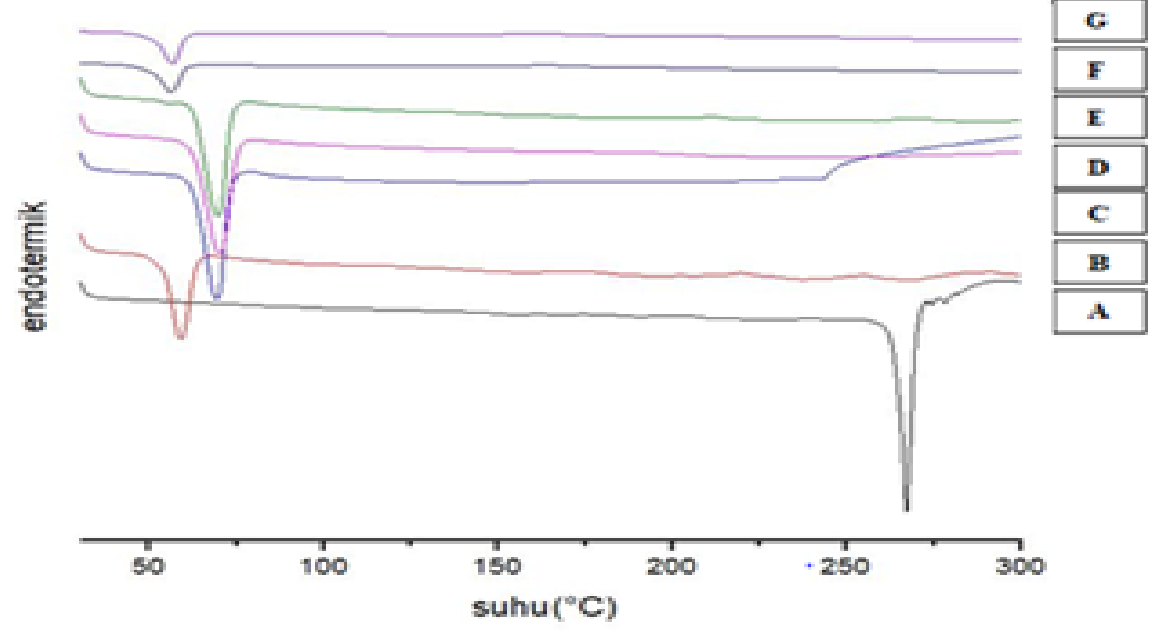

Gambar 2. Perbandingan Termogram (A) MLX, (B) PEG, (C) PLX, (D) CF-1, (E) CF-2, (F) DP-1,(G) DP-2. 
Tabel 3. Bilangan gelombang meloksikam, PEG 6000, poloxamer 188, campuran fisik (99:1) (CF-1), campuran fisik (99:2) (CF-2), dispersi padat (99:1) (DP-1) dan dispersi padat (98:2) (DP-2).

\begin{tabular}{|c|c|c|c|c|c|c|c|}
\hline \multirow{2}{*}{$\begin{array}{l}\text { Gugus } \\
\text { Fungsi }\end{array}$} & \multirow{2}{*}{$\begin{array}{c}\text { Meloksi- } \\
\text { kam }\end{array}$} & \multirow[t]{2}{*}{ PEG 6000} & \multirow{2}{*}{$\begin{array}{c}\text { Poloxa-mer } \\
188\end{array}$} & \multicolumn{2}{|c|}{ Campuran Fisik } & \multicolumn{2}{|c|}{ Dispersi Padat } \\
\hline & & & & CF1 & CF2 & DP1 & DP2 \\
\hline$-\mathbf{N H}$ & 3290,67 & - & - & & & & \\
\hline$-\mathrm{OH}$ & - & 3446,91 & 3466,20 & 3433,41 & 3466,20 & 3462,34 & 3446,91 \\
\hline $\mathbf{C}-\mathbf{H}$ & 2916,47 & 2889,46 & 2887,53 & 2889,46 & 2889,46 & 2889,46 & 2887,53 \\
\hline $\mathbf{C}=\mathbf{N}$ & 1691,63 & - & - & - & - & - & - \\
\hline $\mathrm{C}=\mathrm{O}$ & 1620,26 & - & - & 1633,76 & 1639,55 & 1641,48 & 1639,55 \\
\hline $\mathbf{C}=\mathbf{C}$ & 1548,89 & - & - & - & - & - & - \\
\hline $\begin{array}{c}\mathbf{S}=\mathbf{O} \\
\text { (sulfon) }\end{array}$ & 1346,36 & - & - & 1342,50 & 1344,43 & 1344,43 & 1344,43 \\
\hline $\mathbf{C}-\mathbf{N}$ & 1265,35 & - & - & 1280,78 & 1280,78 & 1280,78 & 1280,78 \\
\hline $\mathbf{C}-\mathbf{O}$ & - & 1112,96 & 1112,96 & 1111,03 & 1111,03 & 1112,96 & 1112,96 \\
\hline
\end{tabular}

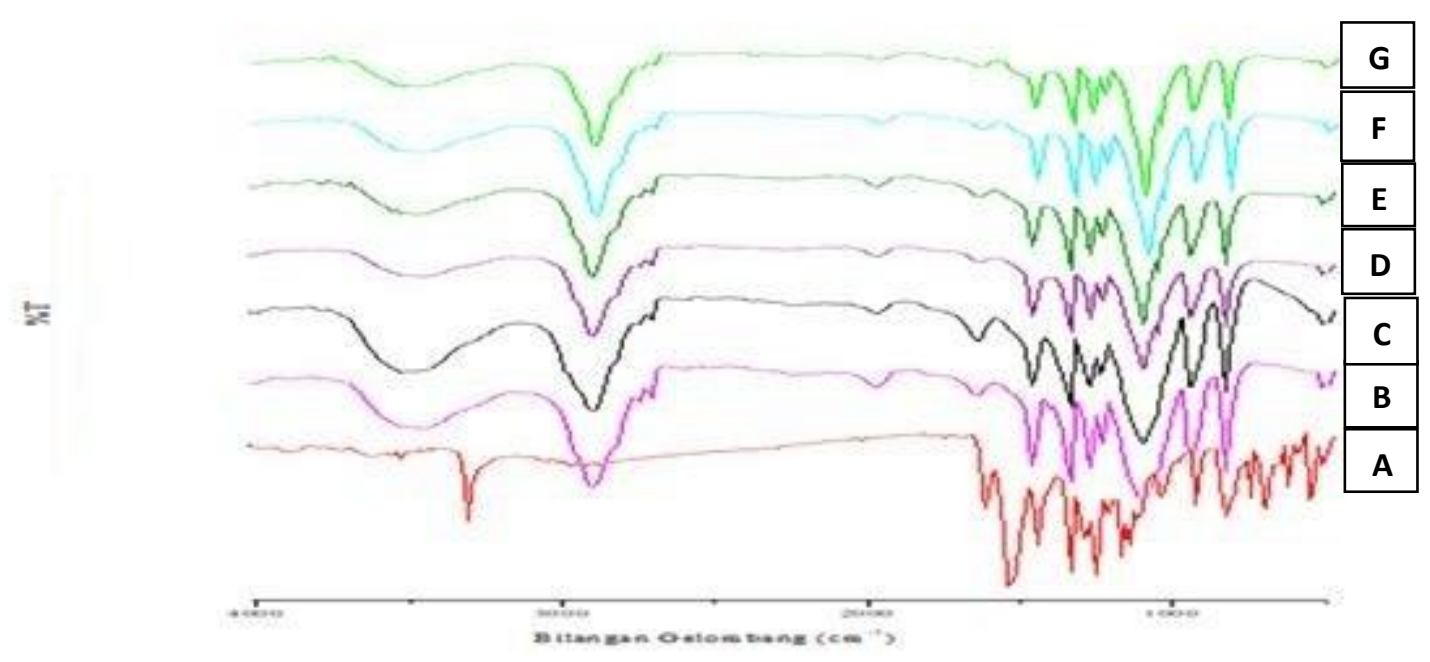

Gambar 3. Perbandingan Spektrum Inframerah (A) MLX, (B) PEG, (C) PLX, (D) CF-1,(E) CF-2, (F) DP-1, (G) DP-2.

\section{Kesimpulan}

Karakterisasi sistem dispersi padat meloksikam dengan matriks PEG 6000 dan poxamer 188 perbandingan (99:1) dan (98:2) dibuat dengan metode peleburan mendapatkan hasil difraktogram sistem dispersi padat meloksikam mengalami hilangnya puncak khas meloksikam. Data termogram DSC sistem dispersi padat meloksikam mengalami penurunan titik lebur dibandingkan dengan senyawa komponen penyusunnya. Hasil data spektra FTIR sistem dispersi padat meloksikam menunjukkan tidak terjadi interaksi yang dapat mempengaruhi struktur meloksikam.

\section{Ucapan Terima Kasih}

Penulis mengucapkan terima kasih kepada Universitas Hang Tuah yang telah memberikan bantuan dana dalam penelitian ini.

\section{Daftar Pustaka}

[1] Sweetman, S.C. 2009. Martindale The Complete Drug Reference. $36^{\text {th }}$ edition. Pharmaceutical Press. USA. Page 81

[2] Katzung BG, Masters SB, Trevor AJ. 2015. Basic \& Clinical Pharmacology $13^{\text {th }}$ Edition. New York: McGraw-Hill. Page 623.

[3] Jouyban, A. 2010. Handbook of Solubility Data for Pharmaceutical. NewYork: CRCPress Taylor \& Francis Group, LLC, pp.382.

[4] Mukhija, U., Soni, N., Chawla, A., \& Bhatt, D. C. 2012. Physical Properties and Dissolution Behaviour of Meloxicam/Poloxamer Solid Dispersions Prepared By Hot Melt Method and Microwave Assisted Method.International Journal of Research in Pharmacy \& Science, Volume 2, Issue 2: 64-74.

[5] Retnowati, D., dan Setyawan, D. 2010. Peningkatan Disolusi Ibuprofen dengan Sistem Dispersi Padat Ibuprofen-PVP K90. Majalah Farmasi Airlangga, Volume 8, Nomor 1: 24-28. 
[6] Kumar, B. 2017. Solid DispersionReview. PharmaTutor, Volume 5, Issue 2: 24-29

[7] Kumari, R., Chandel, P., \& Kapoor, A. 2013. Paramount Role of Solid Dispersion in Enhancement of Solubility. Indo Global Journal of Pharmaceutical Sciences, Volume 3, Issue 1: 78-89.

[8] Sultana, S., dan A. H. M. Saifuddin. 2016. Review Article: Solid Dispersion Currently Practiced in Pharmaceutical Field. International Journal of Advancement in Research and Technology, Volume 5, Issue 3: 170-175.

[9] Kalia, A., \& Poddar, M. 2011. Solid Dispersions: an Approach towards Enhancing Dissolution Rate. Int $j$ pharm pharm sci, Volume 3, Issue 4: 9-19.

[10] Rinaldi, Karsono, Kasmirul Ramlan Sinaga. 2016. The Effect of Solid Dispersion Methods on the Dissolution Profile of Meloxicam. International Journal of PharmTech Research, Volume 9, Nomor 8: 313-31.

[11] Bley, H., Fussnegger, B., \& Bodmeier, R. 2010. Characterization and Stability of Solid Dispersions Based on PEG/polymer Blends. International Journal of Pharmaceutics, Volume 390, Issue 2: 165-173.

[12] Chaudhari, S.P., \& Dugar, R.P. 2017. Application of Surfactants in Solid Dispersion Technology for Improving Solubility of Poorly Water Soluble Drugs. Journal of Drug Delivery Science and Technology, Volume 41: 68-77.
[13] Rowe, C.R., Sheskey, P.J. and Quinn, M.E. (2009). Handbook of Pharmaceutical Excipients, Sixth edition. USA: Pharmaceutical Press.

[14] Prasanthi, N. L., Manikiran, S. S., Sowmya, S., Anusha, B., \& Rao, N. R. 2011. Effect of Poloxamer 188 on In Vitro Dissolution Properties of Antipsychotic Solid Dispersions. International Journal of Pharmaceutical Sciences Review and Research, Volume 10, Issue 1: 15-19.

[15] Issa, A. A., Marchidan, D., Cojocaru, V., \& Anuța, V. 2013. Preparation and evaluation of meloxicam solid dispersion by melting method. Farmacia, Volume 61, Issue 6: 1213-1232.

[16] Wahyuni, R., Halim, A., Oktavia, S. dan Purwaningsih, R. 2017. Pembuatan dan Karakterisasi Dispersi Padat Nifedipin dengan Poloxamer 188 Menggunakan Metode Peleburan. Jurnal Farmasi Higea, Volume 8, Nomor 2: 200-218.

[17] Keerthi S, Rajeshpawan A., Hindustan A.A, Naveena C., Yuvasree S., Venkataramana V, Raghu. 2019. Valuing Best Poloxamer Carrier for Meloxicam Solid Dispersions by novel microwave fusion: Designing and Characterization. Abasyn Journal of Life Science, Volume 2, Issue 1: 1-15.

[18] Wardiyah, W., Asyarie, S. and Wikarsa, S. 2012. Pembuatan dan Karakterisasi Dispersi Padat Sistem Biner dan Terner dari Gliklazid. Acta Pharmaceutica Indonesia, Volume 37, Nomor 3: 95-101. 